\title{
Interphase ribosomal RNA cistron staining in thyroid epithelial cells in Grave's disease, Hashimoto's thyroiditis and benign and malignant tumours of the thyroid gland
}

\author{
N N Mamaev, E N Grynyeva, Y V Blagosklonnaya
}

\begin{abstract}
Aim-To evaluate the expression of ribosomal cistrons in human thyroid epithelial cells (TECs) of patients with Grave's disease, Hashimoto's thyroiditis and benign and malignant tumours of the thyroid gland.
\end{abstract}

Methods-TEC nucleoli were investigated in fine needle biopsy specimens from 10 controls, 39 patients with Grave's disease, 15 with Hashimoto's thyroiditis, 56 with benign, and 15 with malignant tumours of the thyroid. A one step silver staining method was applied. In most cases serum concentrations of thyroxine and triiodothyronine as well as goitre size were determined. In every case 100 TECs were evaluated for the mean numbers of nucleoli and for the average number of argyrophilic nucleolar organiser regions (AgNORs) per nucleus.

Results-NORs were activated in all patients, but not in controls. The numbers of AgNORs in patients with Grave's disease were closely correlated with thyroxine or triiodothyronine, or both, concentrations and with the size of the thyroid. In patients with Hashimoto's thyroiditis about $30 \%$ of TECs nucleoli did not contain AgNORs, whereas others were heavily impregnated with silver. Compared with controls and benign tumours, the nucleoli of carcinomatous TECs were larger and irregular in shape. The mean number of AgNORs per nucleus in malignant cells was higher than that in their benign counterparts.

Conclusions-The mechanism by which NORs are activated in TECs varies depending on the type of lesion. The higher AgNOR score in TECs from malignant tumours can be used to distinguish them from their benign counterparts.

(F Clin Pathol: Mol Pathol 1996;49:M240-M244)

Division of

Endocrinology,

First Department of

Internal Medicine,

Pavlov Medical

University,

Leo Tolstoy str., 6/8,

Leo Tolstoy str., 6/8,
St Petersburg 197089,

Russia

Correspondence to: Dr Nikolai Mamaev.

Accepted for publication 16 January 1996 iser region (AgNOR) staining has been widely described. This technique permits the evaluation of pre-ribosomal RNA transcription by means of light microscopy. ${ }^{1-3}$ As RNA transcription, ribosome formation and protein syn-
Keywords: thyroid disease, thyroid epithelial cells, nucleolar organiser regions, silver staining. thesis are essential, not only for cell proliferation and differentiation but also for general functional status, AgNOR counting is important in the study of many human cell types. Furthermore, as thyroid epithelial cells (TECs) are both hormone producing and hormone dependent cells, they may be suitable subjects for the study of metabolic variation. There are, however, few published papers describing AgNOR behaviour in human TECs. ${ }^{4-14}$ Most studies have been carried out on cells isolated from patients with thyroid tumours. The aim of this paper was to compare the numbers of nucleoli and AgNORs in TECs in healthy subjects and patients with histologically confirmed thyroid disease (Grave's disease, Hashimoto's thyroiditis, and benign and malignant tumours of the thyroid).

\section{Methods}

Thyroid specimens from 29 women and 10 men with Grave's disease, 15 women with Hashimoto's thyroiditis, and 56 patients with benign (all women) and 15 with malignant (three men and 12 women) tumours of the thyroid were studied. In most cases serum concentrations of thyroxine and triiodothyronine, as well as goitre size (graded as recommended by the World Health Organisation (WHO)), were measured.

Twenty six patients with Grave's disease were hyperthyroid. Their diagnosis was based on the typical clinical picture, elevated serum thyroxine and triiodothyronine concentrations, and increased ${ }^{131} \mathrm{I}$ uptake. Clinical examination revealed a soft diffuse goitre in all of the patients and infiltrative ophthalmopathy in $59 \%$. Other clinical features, such as fatigue, loss of weight, increased appetite, tachycardia, and palpitations, were also noted. Mean (SEM) serum thyroxine and triiodothyronine concentrations, measured by radioimmunoassay, were 248 (33.9) $\mathrm{nmol} / \mathrm{l}$ (normal range 60-120 nmol/l) and $3.78(0.32) \mathrm{nmol} / 1$ (normal range $1.17-2.18 \mathrm{nmol} / \mathrm{l})$, respectively. Thirteen patients with Grave's disease were euthyroid, mainly because they had been taking methimazole for five to 36 months before the study was undertaken. Mean (SEM) serum thyroxine and triiodothyronine concentrations in this group were 1311 (72.4) and 1.5 (0.1) $\mathrm{nmol} / \mathrm{l}$, respectively. Goitre sizes were as follows: grade I in one patient; grade II in 23; and grade III in 16 . 
Table 1 Results of silver staining of TECs isolated from controls and patients with thyroid disease. Values are expressed as mean (SEM)

\begin{tabular}{llll}
\hline Diagnosis & $\begin{array}{l}\text { Patients } \\
(n)\end{array}$ & $\begin{array}{l}\text { Nucleoli } \\
(n)\end{array}$ & $\begin{array}{l}\text { AgNORs } \\
(n)\end{array}$ \\
\hline Control & 12 & $1.61(0.07)$ & $5.36(0.36)$ \\
$\begin{array}{l}\text { Grave's disease } \\
\quad \text { Hyperthyroid }\end{array}$ & 26 & $3.52(0.09)^{\star}$ & $9.82(0.24) \dagger$ \\
$\quad$ Euthyroid & 13 & $3.24(0.22)^{\star}$ & $8.34(0.4)^{\star}$ \\
Hashimoto's thyroiditis & 15 & $2.90(0.14)^{\star}$ & $7.87(0.3)^{\star}$ \\
$\quad$ TEC & 15 & $2.56(0.16)$ & $14.25(1.56)$ \\
$\quad$ Lymphocyte & 15 & $2.46(0.11)^{\star}$ & $8.01(0.12) \dagger$ \\
Colloidal goitre & 24 & $2.47(0.11)^{\star}$ & $7.95(0.2) \dagger$ \\
Follicular adenoma & 32 & $2.55(0.22)^{\star}$ & $14.1(0.78) \dagger$ \\
Thyroid cancer & 15 &
\end{tabular}

${ }^{\star} \mathrm{p}<0.05, \mathrm{tp}<0.005 v$ controls $\mathrm{n}=$ number.

All of the patients with Hashimoto's thyroiditis had firm, longstanding goitre, persisting for six months to 30 years (mean 11.1 years). Goiter sizes were grade II in nine patients and grade III in six. Fourteen patients were euthyroid and only one presented with hyperthyroidism. Thyroglobulin antibodies were detected in 10 patients. Titres of 1:320 and higher were regarded as significant and these were found in seven patients. Diagnosis of Hashimoto's thyroiditis was confirmed by fine needle aspiration cytology.

Controls were obtained from two sources. Normal thyroid glands were removed at necropsy from seven patients who had died of ischaemic heart disease. Specimens were also obtained from five volunteers with normal thyroid glands.

Fine needle biopsy specimens of the thyroid were air dried, fixed in 1:3 acetic acid:methanol for 10 minutes and impregnated with silver as described by Howell and Black ${ }^{15}$ with a slight modification ${ }^{14}$ - that is, pretreatment in $2 \mathrm{~N}$ formic acid solution for 10 minutes. Pretreating the specimens with formic acid helps to reduce loss of silver from the nucleoli, making evaluation of the numbers, sizes, and patterns of nucleoli, as well as AgNOR counting, much easier. The preparations were then rinsed in distilled water and lightly counterstained with $2 \%$ Giemsa phosphate buffer $(\mathrm{pH}$ 6.8) for three seconds.

The numbers of nucleoli and of individual AgNOR dots in each cell were counted at a magnification of $\times 1250$. At least 100 interphase cells, chosen at random from each sample, were examined. When AgNORs occurred in large clumps, they were counted approximately, using the area of one typical dot as a standard for determining the possible numbers of AgNORs in each clump. The mean numbers of nucleoli and AgNORs in each nucleus were calculated. The Student's $t$ test was used to compare data in the patient and control groups.

\section{Results}

CONTROLS

The results of AgNOR staining are presented in figs $1 \mathrm{~A}$ and 2 . Each TEC nucleus contained a mean of 1.6 (range 1.34-1.96) nucleoli. The number of AgNORs in nucleoli, corresponding to TEC pre-ribosomal RNA transcription and ribosome maturation, ranged from 1 to 15 per
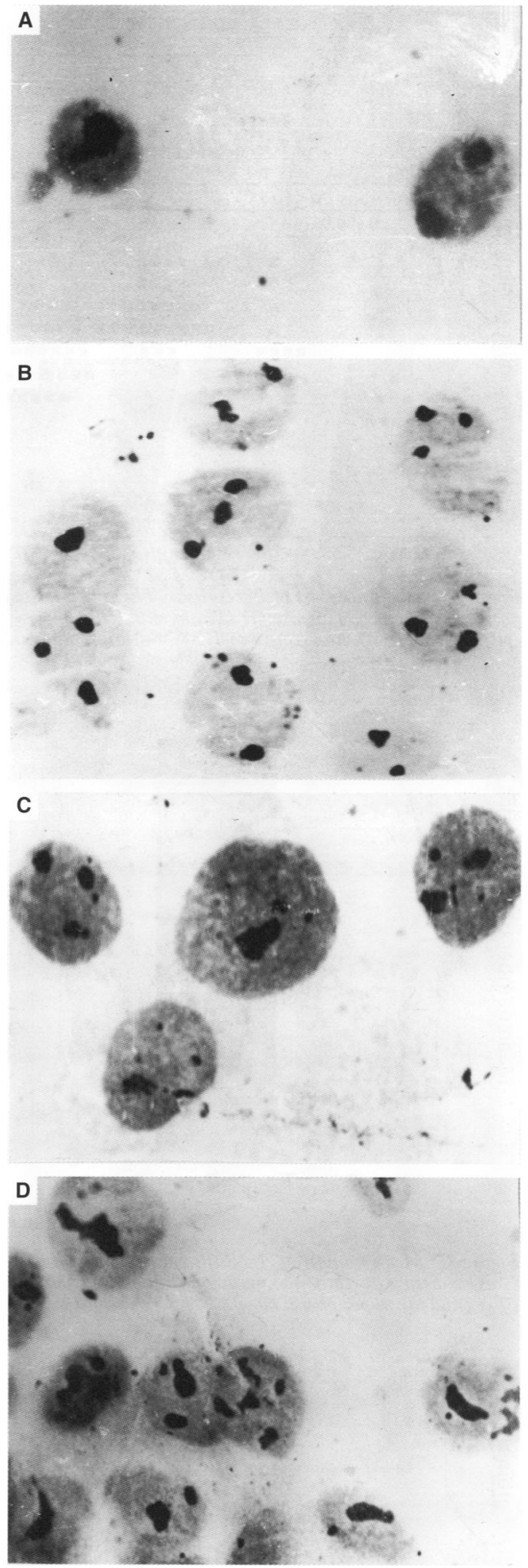

Figure 1 Representative photomicrographs of silver stained TECs in $(A)$ a normal subject, and in patients with (B) Grave's disease, (C) follicular adenoma, and (D) cancer. (Original magnification, $\times 1200$ ).

nucleus. The mean numbers of AgNORs in nucleoli ranged from 3.0 to 6.9 (mean 5.36) per nucleus.

\section{GRAVE'S DISEASE}

TEC nucleoli in patients with Grave's disease were larger than those in controls (fig 1B). Their numbers ranged from one to seven (table 1), significantly higher than in controls. Further analysis of silver stained TECs in the 


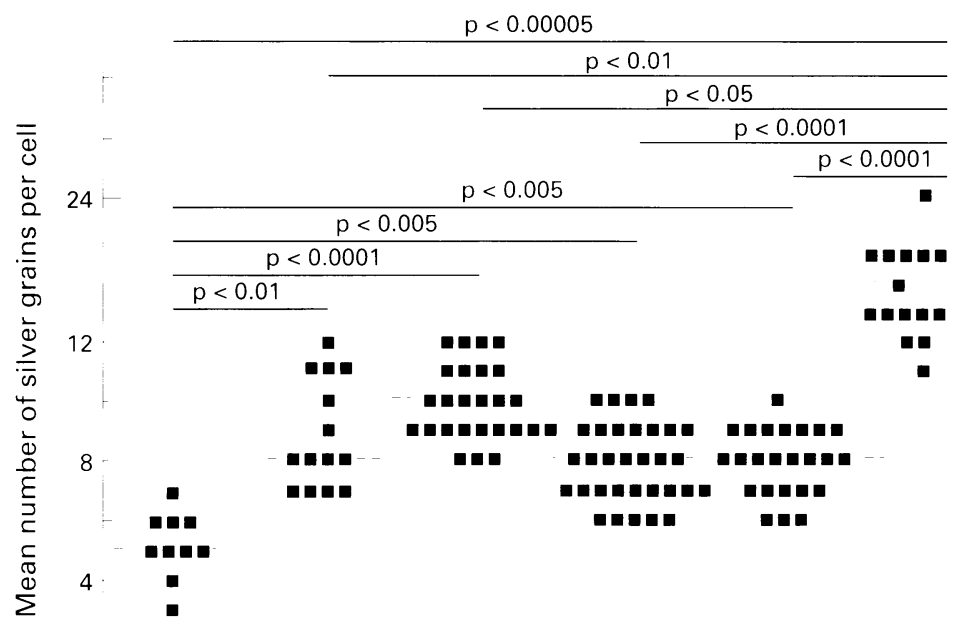

$$
0
$$
I II III IV V VI

Figure 2 Mean numbers of AgNORs in TEC nucleoli isolated from controls (I) and from patients with Grave's disease (II = euthyroid; $I I I=$ hyperthyroid), follicular adenoma $(I V)$, colloidal goitre $(V)$, and cancer (VI).- = mean significance.

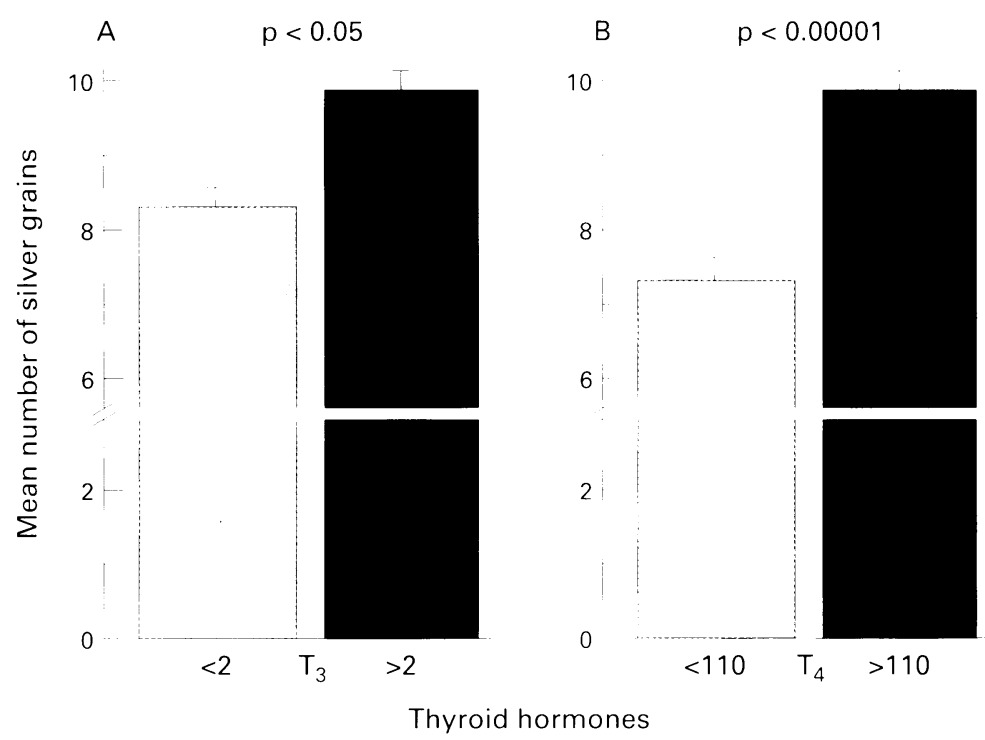

Figure 3 Mean number of AgNORs per nucleus in TECs isolated from patients with Grave's disease in relation to the concentrations of trilodothyronine $\left(T_{\nu}\right)$ and thyroxine $(T),(n m o l / l)$ in peripheral blood.

$p<0.05$

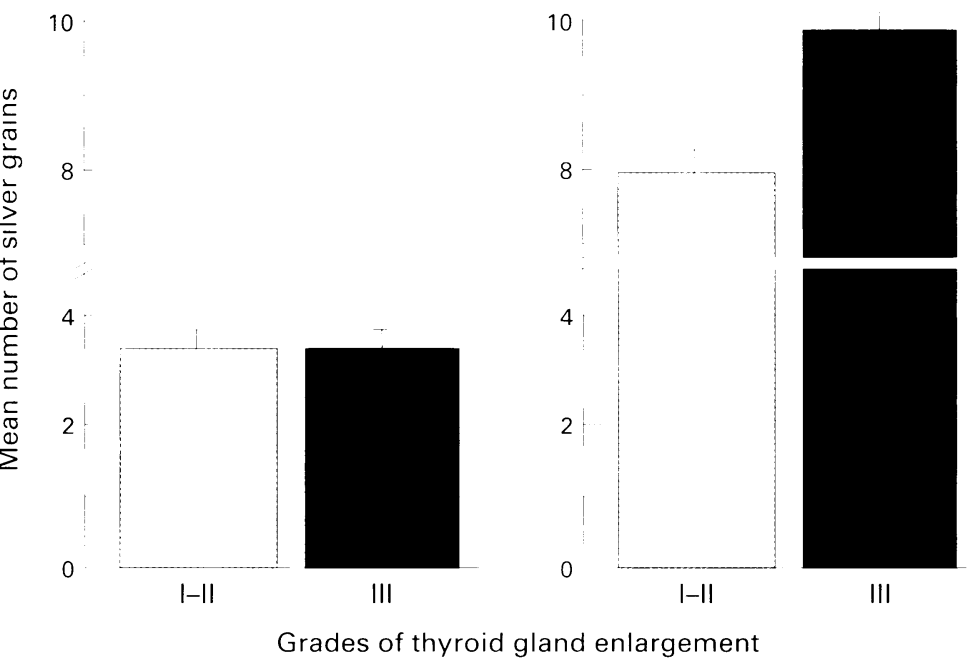
Figure 4 Mean number of (left panel) nucleoli and (right panel) AgNORs in TECS
isolated from patients with Grave's disease (euthyroid) with different grades (I-II or III) of gland enlargement. groups of patients with and without hyperthyroidism revealed that the mean numbers of nucleoli in these cells ranged from 2.5 to 4.3 and from 2.3 to 4.06 (mean 3.5 and 3.24), respectively.

The AgNOR score of TECs in patients with Grave's disease was also higher (figs $1 \mathrm{~B}$ and 2) than in controls and was strongly related to peripheral blood concentrations of thyroxine and triiodothyronine (fig 3). Furthermore, in euthyroid patients a direct association was observed between the number of AgNORs in TEC nucleoli and the size of the thyroid (fig 4). Thus, TEC nucleolar activity in patients with grade III goitre was higher than in those with grades I or II: mean (SEM) $9.26(0.64)$ compared with $7.55(0.24)$ AgNORs per nucleus $(\mathrm{p}<0.05)$.

HASHIMOTO'S THYROIDITIS

The nucleoli of TECs from patients with Hashimoto's thyroiditis were smaller than those from controls and patients with Grave's disease. Their numbers ranged from one to seven (table 1), although occasional TECs contained no nucleoli at all. The mean number of nucleoli in TECs from patients with Hashimoto's thyroiditis ranged from 2.1 to 4.0 per nucleus (mean 2.9). These values were higher than those in controls $(\mathrm{p}<0.0005)$, but lower than those in patients with Grave's disease with and without hyperthyroidism.

The numbers of AgNORs in TEC nucleoli from patients with Hashimoto's thyroiditis ranged from one to 80 per nucleus; $1-30 \%$ of TECs had no AgNORs. The number of TECs ranged from 5.5 to 10.2 per nucleus (mean $7.87)$, significantly higher $(\mathrm{p}<0.001)$ than that in controls but significantly lower ( $\mathrm{p}<$ 0.001) than that in patients with Grave's disease with (mean 9.82) or without (mean 8.34) hyperthyroidism. However, when the numbers of AgNORs were plotted per nucleolus, very similar histogram patterns were produced for patients with Hashimoto's thyroiditis and Grave's disease (fig 5). Interestingly, the highest scores were seen in patients with Hashimoto's thyroiditis and symptomatic hyperthyroidism. Conversely, the lowest scores were found in patients with Hashimoto's thyroiditis without hyperthyroidism.

The AgNOR score was also raised in lymphocytes isolated from patients with Hashimoto's thyroiditis (table 1) (mean 14.25 AgNORs per nucleus). This is presumably beacuse of damage to TECs, resulting in lymphocyte activation.

BENIGN TUMOURS

The results presented in fig $1 \mathrm{C}$ and table 1 show that the mean (SEM) numbers of nucleoli in TECs in patients with nodular goitres $(2.5(0.11))$ and follicular adenomas $(2.5$ $(0.11))$ were higher than those in controls $(1.2$ $(0.07) ; \mathrm{p}<0.05)$. There was also a statistically significant difference $(\mathrm{p}<0.005)$ in TEC AgNOR counts in these three groups $(8.0(0.12), 7.95 \quad(0.2)$ and $5.36 \quad(0.36)$ AgNORs per nucleus). 

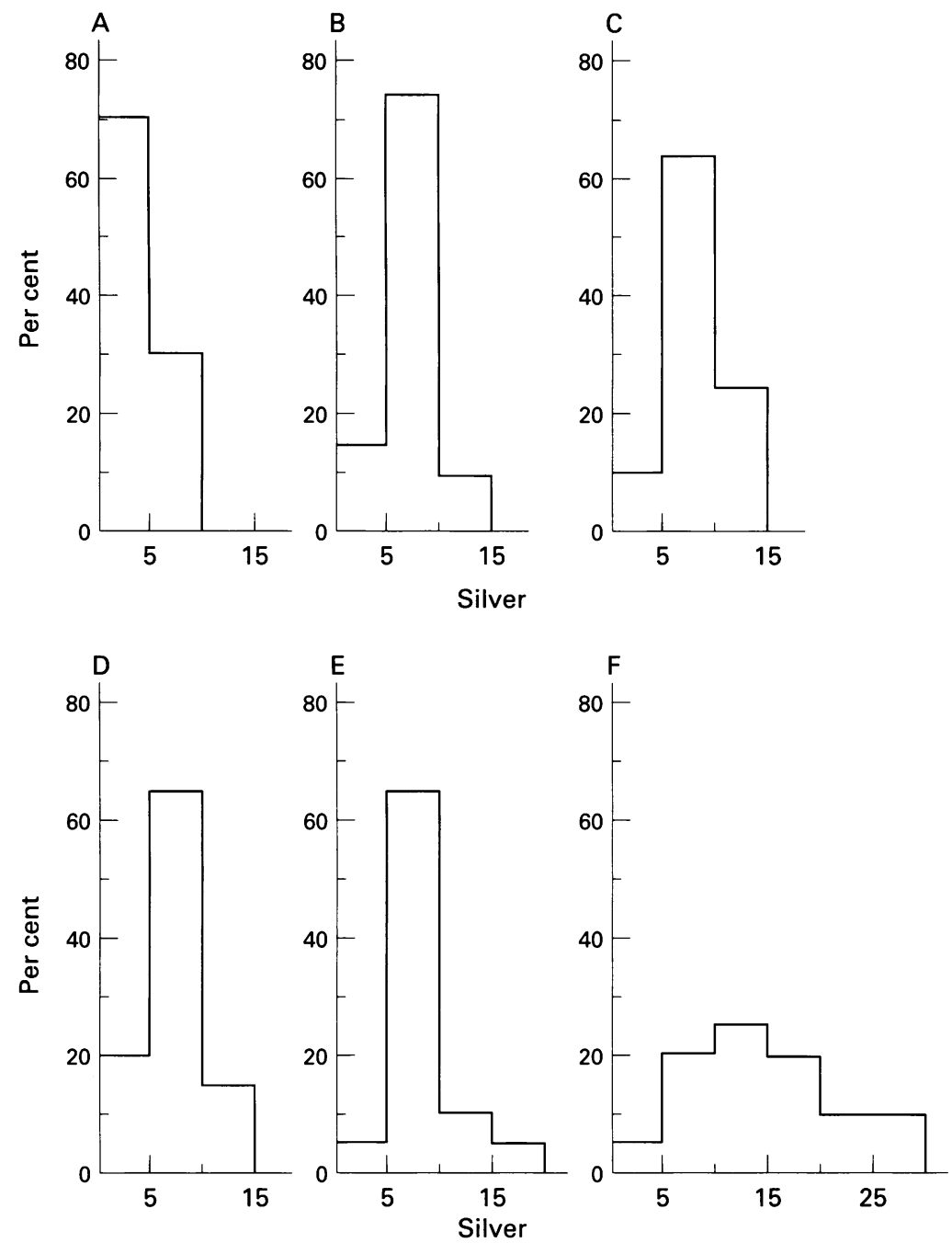

Figure 5 Distribution of TECs with different $A g N O R$ counts in nucleoli from $(A)$ controls and from patients with Grave's disease [(B) euthyroid and (C) hyperthyroid], (D) follicular adenoma, $(E)$ colloidal goitre, and $(F)$ cancer.

THYROID CANCER

TECs isolated from carcinomas contained larger and more irregularly shaped nucleoli than those from benign glands and controls (fig 1D). The mean numbers of nucleoli in malignant cells did not differ from that in follicular adenomas and nodular goitres (table 1).

The mean (SEM) number of AgNORs per nucleus in malignant cells (fig 2) was significantly higher $(14.0(0.8))$ than in controls ( $\mathrm{p}<0.0001$ ) and in benign thyroid lesions $(\mathrm{p}<0.0001)$.

A comparison of the distribution of TECs with different numbers of AgNORs per nucleus (fig 5) showed that in patients with cancer, the modal class was formed by cells with 11 to $15 \mathrm{AgNORs}$ per nucleus. Malignant tumours mainly contained TECs with $>16$ AgNORs per nucleus.

\section{Discussion}

Morphological and functional changes were found in TECs from all patients studied. The mean number of nucleoli was raised in TECs from patients with Grave's disease and Hashimoto's thyroiditis, but large and irregularly shaped nucleoli were mainly found in patients with thyroid cancer. AgNOR scores were highest in patients with malignant thyroid tumours.
AgNOR scores were moderately increased in patients with benign tumours and Hashimoto's thyroiditis.

The proliferative activity of TECs isolated from patients with Grave's disease is minimal, ${ }^{16}$ suggesting that the increase in ribosomal cistron activity may result primarily from TEC hormonal activity and hyperplasia.

The size and argyrophilia of TEC nucleoli in patients with Hashimoto's thyroiditis were more heterogenous than in patients with Grave's disease and controls. Thus about 30\% of TECs from patients with Hashimoto's thyroiditis did not contain AgNORs, whereas others were heavily impregnated with silver. As a result, the mean (SEM) number of AgNORs in TECs from patients with Hashimoto's thyroiditis, containing at least one silver stained nucleolus, was higher (7.9 (0.3); $\mathrm{p}<0.001)$ than that in controls $(5.4(0.36))$ but significantly lower than that in TECs from patients with Grave's disease with and without hyperthyroidism (9.82 (0.24) and $8.34(0.4)$, respectively; $\mathrm{p}<0.001)$. It is worth noting that there was no association between AgNOR scores and the size of the thyroid in patients with Hashimoto's thyroiditis. These findings are in agreement with previous reports that enlargement of the thyroid in patients with Hashimoto's thyroiditis is more closely related to lymphoid infiltration than to TEC hyperplasia.

The mean number of nucleoli in TECs from patients with thyroid tumours did not differ significantly from that in controls, whereas the mean number of AgNORs per nucleus was greatly increased in the former. In our opinion this increase in ribosomal cistron activity in tumour cells may be explained by partial activation of their proliferative potential, which in turn might be stimulated either by oncogenes or by other biologically active substances. ${ }^{17}$

In conclusion, our findings demonstrate that the silver staining method can be used to assess the functional status of human TECs in both physiological and pathological conditions. We believe that AgNOR counting in TECs may prove to be very useful in distinguishing malignant from benign lesions of the thyroid.

1 Crocker J. Nucleolar organizer regions. Curr Top Pathol 1990;82:91-149.

2 Mamaev NN, Mhmaeva SE. Nucleolar organizer region activity in human chromosomes and interphase nuclei of normal, leukemic, and tumor cells as evaluated by silver staining. Int Rev Cytol 1990;121:233-66.

3 Dorenzini $M$, Ploton D. Interphase nucleolar organizer regions in cancer cells. Int Rev Exp Pathol 1991;32:14992.

4 Adnet Jj, Ploton D, Pinteaux A, Lechki C. Les organisateurs nucleolaires en pathologie tumorale. Étude ultrastructurale et optique dans les tumeurs mammaires, thyroidiennes, coliques et uterines. 1re Reunion du GRREPAC. $\mathcal{F}$ Pathol (Paris) 1986;1:14.

5 Adnet JJ, Ploton D, Pinteaux A, Lechki C. Les organisateurs nucleolaires en pathologie tumorale. Étude ultrastructurale et optique dans les tumeurs mammaires, thyroidiennes, coligues et uterines. 69 Congres de l'Association des Anatomistes. Bull Assoc Anat (Nancy) 1987;71:21319.

6 Adnet JJ, Ploton D, Pinteaux A, Monteau M, Dousset H. Argimeration in assessment of thyroid neoplasms. $\mathcal{f}$ Clin Argimeration in asse
Pathol 1988;41:1136.

7 Trerè D, Farabegoli F, Cancelliori C, Eusebi V, Derenzin $M$. AgNOR area in interphase nuclei of human tumours correlates with the proliferative activity evaluated by bromodeoxyuridine labelling and $\mathrm{Ki}-67$ immunostaining. f Pathol 1991;165:53-9. 
8 Rüschoff J. Diagnostic and prognostic significance of histochemical and cytophotometric methods in thyroid tumors. Exp Clin Endocrinol 1993;101:11-16.

9 Rüschoff J, Prasser C, Cortoz T, Hohne HM, Hohenberger W, Hofstadter F. Diagnostic value of AgNOR staining in follicular coil neoplasms of the thyroid: Comparison of follicular coil neoplasms of the thyroid: Comparison of
evaluation methods and nucleolar features. Am $\mathcal{F}$ Surg evaluation methods and

10 Szot W, Szybinski Z, Zaczek M, Kedra D, Dabros E, Piotrowska K, Chlap Z. Fine needle aspiration cytology combined with argyrophllic nucleolar organizer regions (AgNORs) in diagnosis of thyroid neoplasms. Endokrynol Pol 1993;44:413-26.

11 Shem-Tov Y, Straus M, Talmi YP, Rath-Wolfsom L, Zohar Y, Gal R. Nucleolar organizer regions in follicular tumors of the thyroid. Head Neck 1994;16:420-3.

12 Cor A, Pajer Z. Ag-NOR counting for differentiation of follicular thyroid tumours. Pathologica 1994;86:301-3.
13 Mamaev NN, Gryneva EN, Laevskaya ND, Blagosklonnaya YV. Functional activity of human thyrocytes in Grave's disease, Hashimoto's thyroiditis and thyroid nodules as disease, Hashimoto's thyroiditis and thyroid nodules as
evaluated by nucleolar silver staining (in Russian). Arkh Patol 1994;56:58-61.

14 Mamaev NN, Gryneva EN, Blagosklonnaya YaV. Expression of ribosomal genes in human thyrocytes [abstract]. the Wilhelm Bernard Workshop. The 14th International Workshop on the Cell Nucleus, 1995 May 27-31; Spa, Belgium, 1995:68

15 Howell WM, Black DA. Controlled silver staining of nucleolus organizer regions with propective colloidal developer: a 1-step method. Experientia 1980;36:1014-15.

16 Derwahl M, Huber G, Studer H. Slow growth intense hypertrophy of thyrocytes in long-standing Grave's goitres. Acta Endocrinol 1989;121:389-94.

17 Farid NR, Shi Y, Zou M. Molecular basis of thyroid cancer. Endocr Rev 1994;15:202-32. 